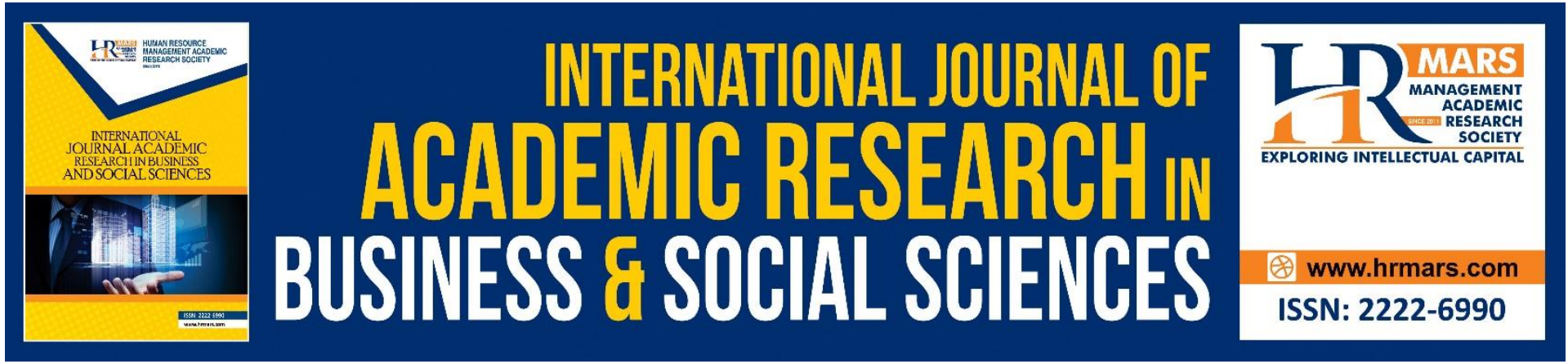

\title{
The Effect of Culinary Tourism on Tourists' Loyalty and Satisfaction: A Comparison Analysis Between the First and Revisit to Malaysia
}

Sharul Shahida Shakrein Safian, Adibah Alawiah Osman, Siti Norida Wahab, Norashida Othman, Nur Azirah Zahida Mohamad Azhar

To Link this Article: http://dx.doi.org/10.6007/IJARBSS/v11-i8/10535 DOI:10.6007/IJARBSS/v11-i8/10535

Received: 08 June 2021, Revised: 30 June 2021, Accepted: 12 July 2021

Published Online: 05 August 2021

In-Text Citation: (Safian et al., 2021)

To Cite this Article: Safian, S. S. S., Osman, A. A., Wahab, S. N., Othman, N., \& Azhar, N. A. Z. M. (2021). The Effect of Culinary Tourism on Tourists' Loyalty and Satisfaction: A Comparison Analysis Between the First and Revisit to Malaysia. International Journal of Academic Research in Business and Social Sciences, 11(8), 154-167.

\section{Copyright: (c) 2021 The Author(s)}

Published by Human Resource Management Academic Research Society (www.hrmars.com) This article is published under the Creative Commons Attribution (CC BY 4.0) license. Anyone may reproduce, distribute, translate and create derivative works of this article (for both commercial and non-commercial purposes), subject to full attribution to the original publication and authors. The full terms of this license may be seen at: http://creativecommons.org/licences/by/4.0/legalcode

Vol. 11, No. 8, 2021, Pg. 154 - 167

Full Terms \& Conditions of access and use can be found at http://hrmars.com/index.php/pages/detail/publication-ethics 


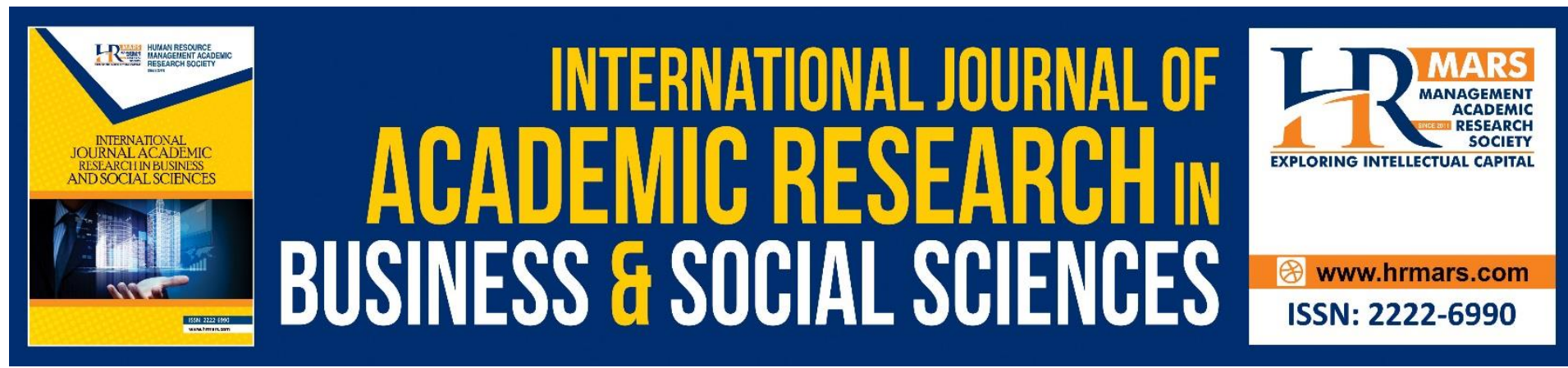

\title{
The Effect of Culinary Tourism on Tourists' Loyalty and Satisfaction: A Comparison Analysis Between the First and Revisit to Malaysia
}

\author{
Sharul Shahida Shakrein Safian, Adibah Alawiah Osman, \\ Siti Norida Wahab, Norashida Othman, Nur Azirah Zahida \\ Mohamad Azhar \\ Faculty of Business and Management, University Teknologi MARA, Puncak Alam Campus \\ 42300 Selangor, Malaysia \\ Email: sharulshahida@uitm.edu.my, adibahalawiah@uitm.edu.my, \\ sitinorida23@uitm.edu.my,shidaothman@uitm.edu.my, azirahazhar@uitm.edu.my
}

\begin{abstract}
Although there is a growing awareness of the relationship between food and tourism, there is little empirical evidence documenting the perception and satisfaction among tourists that visit Malaysia. The purpose of this study is to investigate the relationship between the destination's food image, destination physical image and information sources with the intention to visit and revisit the same place. At the same time, this study is regarding tourists' satisfaction and loyalty with food and culture in Malaysia. A survey was carried out via online survey and total of 250 tourists from various background and nations were obtained using a random sampling approach analysed using SPSS. Malaysia has the potential of being a food tourism destination and viewed as a melting pot of cultural food variety as well as the existence of various cultural backgrounds. The findings also show that culinary tourism has significantly effect on tourists' satisfaction and loyalty with Malaysian food as well as behavioural intention. As a result, it explains why tourists have such a deep urge to come back. Unlike previous studies, this study compares the findings of a group of revisits to suggest a more integrated tourist loyalty. The findings support the notion of returning to Malaysia to experience the country's unique food culture. Further study can be conducted more effective by using aspect of different cultures have different perception and evaluation frameworks for food as well as tourism promotion should be customized so another future research would be conducting extensive studies in country based on various cultures and background of states to identify the motivating factors.
\end{abstract}

Keywords: Culinary Tourism, Loyalty, Satisfaction, Transportation, Revisit

\section{Introduction}

Culinary tourism is one of the most important tourism industries. Culinary tourism tells stories about a region's history, inhabitants, and landscape (Sotiriadis, 2015). It reflects 
'place', which in this study is 'Malaysia', enriches experiences, and can be a useful tool for boosting economic, social, and community growth. Furthermore, some argue that culinary tourism is a niche market with the potential to inspire and draw visitors' intentions to visit (Sidali et al., 2013). Culinary tourism refers to trips to destinations where the key driving factors are local food and beverages. In other words, as compared to other factors such as demographics and physical accessibility, Malaysia's food and beverages would be the primary reason for visitors to visit. Food is an undeniable necessity for vacationers, as well as a daily basic requirement for all humans. Culinary tourism now has tremendous potential to make the tourism industry a valuable component of most countries' growth and development plans. During their journeys, a large percentage of travellers consider dining and food to be important activities. However, the importance of food in destination marketing has received little attention until recently, both globally and locally (Bokunewicz and Shulman, 2017).

Culinary tourism is the pursuit of one-of-a-kind and unforgettable dining and drinking experiences. In other words, it is made up of tourists' perceptions and satisfaction with the taste and tastes of food and beverages (Björk and Kauppinen-Räisänen, 2016). To achieve maximum satisfaction among visitors, it is critical to serve and prepare not only a variety of foods but also interesting cuisines. As a result, it will have a major effect on customer loyalty and improve the quality of our country's tourism services. Furthermore, it is critical in attracting more tourists to Malaysia, as it will contribute significantly to the level of loyalty and consistency with which the same tourists return to Malaysia (Musa, 2000).

Even though culinary tourism is a significant part of the tourism industry, it is still a field where many researchers have not done extensive research (Lee et al., 2015). In 1998, Lucy Long coined the phrase 'culinary tourism', which she defines as 'the experience and participation of other people in foodways', or 'testing and trying various types of cuisines from a different context (country). It is not limited to the consumption, preparation, and presentation of food products' (Long, 2004). Culinary tourism encompasses not only the study of the tourism industry but also many related fields such as food trade and distribution in the tourism industry. Furthermore, our county can benefit from the culinary tourism industry by providing more opportunities for entrepreneurs, especially small and medium-sized businesses (SMEs), to participate in the food trading industry. As a result, it will increase the level of creativity among entrepreneurs in presenting and promoting Malaysian food products to tourists and the rest of the world. In this sector, which is indirectly linked to culinary tourism, there is still a lack of research and development (Chi et al., 2013).

\section{Literature Review}

According to the findings of this research, no particular theory was used to clarify or direct the study framework. The majority of previous studies used behavioural economics concepts and literature reviews as a theoretical basis, and this analysis will be focused on consumer taste and preferences in food and tourism. Thielke et al. (2012) used Maslow's theory as the foundation of his research into food consumption behaviour. It can be described as the satisfaction of basic needs to actual needs. To put it another way, the theory was used to describe the relationship between the idea of human needs and the actual state of those needs.

Food serves a variety of purposes in meeting human needs as well as satisfying taste and preference preferences. Both of these roles influenced our eating habits. According to some authors, people in the United States prefer to be satisfied when consuming food not only for basic psychological needs but also for the presentation of food when dining out 
(Hwang, 2016; Guthrie et al., 2015). Similarly, Mak et al. (2012) and Rajendran et al. (2017) discovered that food is not only essential for eating. It is also includes other complementary elements. For instance traditions, personal identity, processing, sustainability and consumption. Culinary has also been recognised as a significant element in the tourism industry. It has been utilized in advertisements promoting restaurant, hotel, and destination items. According to Ji et al (2016); Chang et al (2011), the travellers' level of satisfaction with the trip was affected by food. It can conclude that the quality of the food has a big effect on overall satisfaction with the visit. Hendijani (2016) found that food was a big factor in why people returned to Indonesia. Furthermore, the authors discovered that, in addition to overall satisfaction, food is the main element that influences traveller satisfaction. Alike, Seo and Yun (2015) in their study highlighted that food was the key factor to revisit. It is after weather, lodging, and scenery. Overall, it was discovered that food had a huge impact on travellers' overall perceptions of a destination and their satisfaction with it.

The relationship between food and tourism can be defined as mutually dependent, as the culinary tourism industry grows in importance in the country. Previous study has indicated that tourists spend most of their travel consumption on food (Liang et al., 2013). It demonstrates that food and the tourism industry have a symbiotic relationship and are mutually dependent. Above all, food has long been known as a powerful marketing and positioning tool for a destination (Lee and Arcodia, 2011). Similarly, as interest in regional cuisine grows, in order to increase its appeal, destinations that concentrating on food as their primary tourism commodity increasing. For example, Italy, Thailand and France are renowned for their cuisine, and their cuisine has its own identity. In the case of Malaysia, our cuisines are distinguished by their cultural and geographic origins, as well as by ethnicity, state demographic region, and history. At the same time, food has commercialised tourism in some Malaysian areas in comparison to their physical demographics (Zakaria et al., 2014).

Food, according to Everett and Slocum (2013), is more than a basic need for visitors. It is also a culture identity that can improve a destination portray itself positively. Food can be element to represent a destination's identity and culture. Furthermore, it can also be element in the creation of a destination's reputation. In other words, food can be a key component in gaining valuable tourist perceptions, especially in terms of culture and heritage. Food was not only a necessity for them while travelling, but also an investment that they were willing to make in order to provide unforgettable dining experiences. As a consequence, it will promote positive perceptions of the nation. Furthermore, food consumption benefits a destination's economy and provides visitors with a unique local experience. The increasing number of restaurants that offer a variety of cuisines are due to the tourist arrivals in most countries are rising. It is the fact that, to experience and taste the food is one of the main reasons people travel (Hjalager et al., 2013; Hendijani, 2016).

Tourism and culinary tourism have a close correlation, as shown by destination marketing campaigns around the world (Bokunewicz and Shulman, 2017). However, there is a lack of empirical evidence to support the presence of the culinary-tourism business segment. It's also important to know if the culinary offerings of a destination contribute to the tourists' overall satisfaction with their visit. In terms of loyalty, we can tell whether tourists return to a destination to resample or retry its cuisine, so it's interesting to look at how much they visit or repeat to see how satisfied they are. In either case, culinary plays a significant role in how visitors view a destination, with some travellers indicating that they will return to the same location to sample its special cuisine. 
Furthermore, a destination's food can be used to reflect the destination's picture and uniqueness. As a result, in order to create a potential picture, it is highly desirable by defining and positioning a particular product for the market. Culinary tourism not only appeals to visitors, but it also helps a destination's social, economic, and environmental development (Wahab et al., 2017). Based on the author's perspective, other factors that supported the role of culinary in the growth of the tourism industry include a greater emphasis on the picture of food as the primary commodity on the market. Furthermore, according to the other author, those regions that can provide and market their food as a premier tourism commodity would benefit the most from the increase in value of their destinations. Despite the fact that food remains a significant aspect of tourism, there is still a lack of empirical studies to back it up, as well as the industry's inability to attract many researchers in this area (Zaman et al., 2016).

Ecotourism, ethnic, cultural, sports, health, and other sectors comprise the tourism industry as a whole. Both of these forms of tourism can generate various types of experiences. Culinary tourism is linked to food and eating experiences, and one of the key elements of the tourism industry that occurs as people travel all over the world is to have unforgettable and valuable food and drink experiences (Long, 2004). Additionally, during a trip or holiday, there will be several travellers who are eager to try new foods or learn about different cultures, as well as others who are curious about different foods. Some travellers, on the other hand, may prefer foods that are similar to those they eat at home. The issue or problem that arises as a result of certain causes or factors leading to different types of taste and preferences among travellers would be the issue or problem that arises from these two opposing situations (Horng and Tsai, 2011).

In terms of views, there are a variety of viewpoints on food and tourism, and the relationship between the two seems to be paradoxical. Food can be associated with a variety of experiences, and it can fulfil a variety of functions, ranging from essential needs to providing entertainment (Björk and Kauppinen-Räisänen, 2016), social and cultural needs (Zakaria et al., 2014), social status needs (Mak et al., 2012), various experience (Long, 2004) and other roles. In other words, the issue arises when the situation for understanding tourist behaviour in the food tourism industry is to concentrate on the investigation of their taste and desires in order to obtain maximum satisfaction. Furthermore, there has been very little research on the role of food in tourism in terms of destination food image, destination physical image, knowledge sources, and loyalty among Asia countries. Thus, the aim of this study is to look into the impact of a culinary destination's food appearance, physical image, knowledge sources, loyalty (revisit), and demographic profiles on a traveller's intention to return.

\section{Methodology}

To measure the food experience, physical experience and information sources of tourists during their vacation in Malaysia. It is self-administrated questionnaires with four parts (socio-demographic factors, destination's food image, destination's physical image and information sources) were distributed randomly among tourists via online survey. In this study, the focus respondents were tourists that had visit Malaysia more than once. The instrument was designed based on a review of the literature. The questionnaire was developed in order to investigate the objectives of this study. The survey was valuable to examine a better understanding of tourists' perspective regarding a destination's food image, destination's physical image and information sources. It is particularly when decisions for a 
vacation was made. Furthermore, it was measured the level of satisfaction and loyalty of tourists when comparing two different groups from the questionnaires.

The questionnaire divided into four parts. It was included several categories of questions: social demographic characteristics and factors, destination's food image, destination's physical image, information sources, and the importance of overall attributes, first-timer visitors and intention to revisit. Every section has some attributes that represent the main variable. A five-point Likert scale ranged from $1=$ "strongly disagree" to $5=$ "strongly agree". As a result, 250 valid questionnaires were obtained after removing incomplete responses. In subsequently, the analysis continued to examine the tourists' overall satisfaction and loyalty among tourists that visit Malaysia during that period. A frequency and t-test analysis were undertaken. It is to finalize the condition of statistically significant difference between the ratings of first-time and revisit tourists on attributes. Data analysis was divided into three parts. It is explaining by descriptive and inferential statistics. The data was analysed using The Statistical Package for Social Science (SPSS).

\section{Results and Discussion}

Demographic of Respondents

Table 1 depicted the demographic profiles of overall 250 respondents. The respondents' gender was almost equally distributed. It is with $50.4 \%$ male and $49.6 \%$ female which is 126 male and 124 females. The respondents' age was between 21 to 30 years (28.0\%) as highest rate. Then followed by $31-40$ years (26.8\%), while 51 years and above (18.8\%). Few respondents were $41-50$ years $(15.2 \%)$ and $(11.2 \%)$ for 20 years and below. Based on monthly income among respondents reported that most of them earned RM5001 and above (44.0\%) followed by other range RM4001- RM5000 about (19.2\%), RM3001-RM4000 about (17.6\%), RM2001-RM3000 about (12.8\%) and the lowest (6.4\%) for RM2000 and below. Half of the respondents were married (50\%) and vice versa. Most of the respondents had a degree and diploma which is $(41.6 \%)$ and $(46.8 \%)$, while only $12.2 \%$ had a graduate/post-graduate degree. In term of the purpose of the study, most of the respondents reported that the purpose of the visit was leisure about $(66.8 \%)$ then followed by visiting family members or friends $(10.4 \%)$, business or academic purposes $(9.2 \%)$ while the lowest rate $(6.8 \%)$ goes to attending special occasions and others. Based on the overall demographic of the respondent's profile we could know the trend and frequency in every characteristic. 
Table 1. Tourist's Profile

\begin{tabular}{|c|c|c|c|}
\hline \multicolumn{2}{|c|}{ Level } & Frequency & Percentage \\
\hline \multirow[t]{2}{*}{ Gender } & Male & 126 & 50.4 \\
\hline & Female & 124 & 49.6 \\
\hline \multirow[t]{5}{*}{ Age } & Under 20 & 28 & 11.2 \\
\hline & $21-30$ & 70 & 28.0 \\
\hline & $31-40$ & 67 & 26.8 \\
\hline & $41-50$ & 38 & 15.2 \\
\hline & $51 \&$ above & 47 & 18.8 \\
\hline \multirow[t]{5}{*}{ Monthly Income } & Less RM2000 & 16 & 6.4 \\
\hline & RM2001-RM3000 & 32 & 12.8 \\
\hline & RM3001-RM4000 & 44 & 17.6 \\
\hline & RM4001-RM5000 & 48 & 19.2 \\
\hline & RM5001 \& above & 110 & 44.0 \\
\hline \multirow[t]{2}{*}{ Marital Status } & Single & 125 & 50.0 \\
\hline & Married & 125 & 50.0 \\
\hline \multirow[t]{4}{*}{ Level of Education } & Pre-degree/Diploma & 117 & 46.8 \\
\hline & Degree & 104 & 41.6 \\
\hline & Master & 28 & 11.2 \\
\hline & PhD & 1 & 0.4 \\
\hline \multirow[t]{5}{*}{ Purpose of Visit } & Leisure & 167 & 66.8 \\
\hline & Business/Academic Purposes & 23 & 9.2 \\
\hline & Attending Special Occasions & 17 & 6.8 \\
\hline & Visiting family members/friends & 26 & 10.4 \\
\hline & Others & 17 & 6.8 \\
\hline
\end{tabular}

Comparison between Tourist's (First timer and More than once)

Table 2 displayed the mean ratings of the destination's food images. The mean range was scores from 4.00 to 5.00 . As a result, all of the attributes were perceived positively by the respondents. 18 attributes were in the high end. Based on comparison between first-timer visitors and more than once visitors reported that mean for this variable was 4.23 and 4.35 which is also high mean score as the value close to 5.0 and the total variability for both groups of visitors showed 0.653 for first-timer group while 0.715 for more than once group. In term of frequency, based on the comparison between two different groups reported that the firsttimer group had chosen the destination's food images as "important" at 55.1\% while $46.2 \%$ from more than once the group had chosen "mostly important". In a conclusion, mean and total variation for destination's food images showed the significant effect of variable in this study.

Table 2. Destination's food images comparison

\begin{tabular}{ccccccccc}
\hline $\begin{array}{c}\text { Destination's Food } \\
\text { Images }\end{array}$ & \multicolumn{3}{c}{$\mathbf{1}^{\text {st }}$ timer } & \multicolumn{5}{c}{ More than once } \\
\hline Mostly unimportant & 0 & 0 & 4.23 & 0.653 & 1 & 0.7 & 4.35 & 0.715 \\
Unimportant & 1 & 0.9 & & & 1 & 0.7 & & \\
Uncertain & 10 & 9.3 & & & 11 & 7.7 & & \\
Important & 59 & 55.1 & & & 64 & 44.8 & & \\
Mostly important & 37 & 34.6 & & & 68 & 46.2 & & \\
\hline
\end{tabular}


Table 3 displayed the mean ratings of the destination's physical images. The mean range was scores from 3.00 to 4.00 . As a result, all of the attributes were perceived positively by the respondents. 12 attributes were in the high end. Based on comparison between first-timer visitors and more than once visitors reported that both mean for this variable was 3.73 which is also not so high mean score as the value close to 4.0 and the total variability for both groups of visitors showed 0.734 for first-timer group while 0.607 for more than once group. In term of frequency, based on the comparison between two different groups reported that both group first-timer and more than once group had chosen destination's food images as "important" at $47.7 \%$ and $55.9 \%$. As a conclusion, mean and total variation for destination's physical images showed the significant effect of variable in this study but at the low rating compared to previous destination's food images.

Table 3. Destination's physical images comparison

\begin{tabular}{ccccccccc}
\hline $\begin{array}{c}\text { Destination's Physical } \\
\text { Images }\end{array}$ & Freq. & $\mathbf{9}$ & Mean & SD & Freq. & $\%$ & Mean & SD \\
\hline Mostly unimportant & 0 & 0 & 3.37 & 0.734 & 0 & 0 & 3.73 & 0.607 \\
Unimportant & 3 & 2.8 & & & 0 & 0 & & \\
Uncertain & 38 & 35.5 & & & 51 & 35.7 & & \\
Important & 51 & 47.7 & & & 80 & 55.9 & & \\
Mostly important & 15 & 14.8 & & & 12 & 8.4 & \\
\hline
\end{tabular}

Table 4 displayed the mean ratings of information sources. The mean range was scores from 3.00 to 4.00 . As a result, all of the attributes were perceived positively by the respondents. 12 attributes were in the high end. Based on comparison between first-timer visitors and more than once visitors reported that both means seems very close for this variable were 3.55 and 3.53 which is also not so high mean score as the value close to 4.0 and the total variability for both group of visitors showed 0.780 for first-timer group while 0.767 for more than once group. In term of frequency, based on the comparison between two different groups reported that both group first-timer and more than once group had chosen information sources as "uncertain" at $45.8 \%$ and $51.0 \%$. As a conclusion, mean and total variation for information sources showed the significant effect of variable in this study but at the low rating compared to previous destination's food images and destination's physical images.

Table 4. Information Sources comparison

\begin{tabular}{ccccccccr}
\hline \multirow{2}{*}{ Information Sources } & \multicolumn{4}{c}{$\mathbf{1}^{\text {st }}$ timer } & \multicolumn{5}{c}{ More than once } \\
& Freq. & $\mathbf{\%}$ & Mean & SD & Freq. & $\%$ & Mean & SD \\
\hline Mostly unimportant & 1 & 0.9 & 3.55 & .780 & 0 & 0 & 3.53 & .767 \\
Unimportant & 4 & 3.7 & & & 6 & 4.2 & & \\
Uncertain & 49 & 45.8 & & & 73 & 51.0 & & \\
Important & 41 & 38.3 & & & 46 & 32.2 & & \\
Mostly important & 12 & 11.2 & & & 18 & 12.6 & \\
\hline
\end{tabular}

\section{F-Test Regression}

Table 5 showed the comparison of Destination's food images attributes between first-timer visitors and more than once visitors based on the result of F-test regression. Based on the result showed that all attributes were significantly affected $(p<0.001)$ the destination's food images for more than once visitors while for first timer visitors showed the attributes of "The 
most popular cuisine in the world" as $p=0.478$ and "Various food activities" as $p=0.233$ which mean insignificantly effect of this variable. On the other hands, all attributes showed a positive value of beta for both group first-timer and more than once visitors. For instance, changing the most popular cuisine in the world by one SD while holding other attributes constant would change the dependent variable by 0.069 SD.

Table 5. Destination's food images f-test regression

\begin{tabular}{|c|c|c|c|c|c|c|}
\hline \multirow[b]{2}{*}{ Destination's Food images } & \multicolumn{3}{|c|}{$1^{\text {st }}$ timer $(\mathrm{N}=107)$} & \multicolumn{3}{|c|}{ More than once $(\mathrm{N}=143)$} \\
\hline & beta & $\begin{array}{c}\text { t- } \\
\text { value }\end{array}$ & sig. & beta & t-value & sig. \\
\hline $\begin{array}{l}\text { The most popular cuisine in the } \\
\text { world }\end{array}$ & .069 & .712 & .478 & .356 & 4.518 & .000 \\
\hline Variety of food & .160 & 1.656 & .101 & .416 & 5.429 & .000 \\
\hline Good quality of food & .369 & 4.064 & .000 & .500 & 6.848 & .000 \\
\hline Reasonableprice for dining-out & .365 & 4.016 & .000 & .559 & 7.998 & .000 \\
\hline Packages of tour related tofood & .383 & 4.244 & .000 & .409 & 5.324 & .000 \\
\hline Many attractive restaurants & .368 & 4.051 & .000 & .568 & 8.194 & .000 \\
\hline Uniquecultural experiences & .463 & 5.352 & .000 & .466 & 6.262 & .000 \\
\hline Easy access to restaurants & .327 & 3.549 & .001 & .474 & 6.384 & .000 \\
\hline Variety ofspecialty restaurants & .327 & 3.549 & .001 & .488 & 6.632 & .000 \\
\hline Regionally produced foodproducts & .342 & 3.723 & .000 & .430 & 5.660 & .000 \\
\hline Restaurant'smenu in English & .324 & 3.509 & .001 & .441 & 5.842 & .000 \\
\hline Opportunity tovisit street markets & .350 & 3.825 & .000 & .433 & 5.708 & .000 \\
\hline Unique street food vendors & .308 & 3.319 & .001 & .371 & 4.748 & .000 \\
\hline Various food activities & .116 & 1.200 & .233 & .272 & 3.362 & .001 \\
\hline Much literature on food & .308 & 3.313 & .001 & .449 & 5.973 & .000 \\
\hline
\end{tabular}

Table 6 showed the comparison of Destination's food images attributes between first-timer visitors and more than once visitors based on the result of F-test regression. Based on the result showed that all attributes were significantly affected $(p<0.001)$ the destination's food images for more than once visitors while for first timer visitors showed the attributes of "The most popular cuisine in the world" as $p=0.478$ and "Various food activities" as $p=0.233$ which mean insignificantly effect of this variable. On the other hands, all attributes showed a positive value of beta for both group first-timer and more than once visitors. For instance, changing the most popular cuisine in the world by one SD while holding other attributes constant would change the dependent variable by 0.069 SD. 
Table 6. Destination's physical images f-test regression

\begin{tabular}{|c|c|c|c|c|c|c|}
\hline \multirow[b]{2}{*}{ Destination's Physical images } & \multicolumn{3}{|c|}{$1^{\text {st }}$ timer $(\mathrm{N}=107)$} & \multicolumn{3}{|c|}{ More than once $(\mathrm{N}=143)$} \\
\hline & beta & $\begin{array}{c}\text { t- } \\
\text { value }\end{array}$ & sig. & beta & t-value & sig. \\
\hline Service and managementquality & .453 & 5.213 & .000 & .438 & 5.778 & .000 \\
\hline $\begin{array}{l}\text { Promotion oroffer from tourism } \\
\text { festival }\end{array}$ & .429 & 4.867 & .000 & .186 & 2.250 & .026 \\
\hline Kindness ofpeople in Malaysia & .384 & 4.266 & .000 & .370 & 4.730 & .000 \\
\hline Cultural andheritage background & .439 & 5.000 & .000 & .454 & 6.043 & .000 \\
\hline Variety of places to visit & .403 & 4.515 & .000 & .445 & 5.899 & .000 \\
\hline Peacefulness andstability in Malaysia & .299 & 3.216 & .002 & .439 & 5.794 & .000 \\
\hline $\begin{array}{c}\text { Easy and comfortable to dining- } \\
\text { out }\end{array}$ & .522 & 6.273 & .000 & .351 & 4.452 & .000 \\
\hline Entertainment availability & .468 & 5.420 & .000 & .168 & 2.028 & .044 \\
\hline $\begin{array}{l}\text { Consistent social networking by } \\
\text { authority }\end{array}$ & .341 & 3.716 & .000 & .480 & 6.496 & .000 \\
\hline Unique andmemorable places & .518 & 6.213 & .000 & .460 & 6.159 & .000 \\
\hline $\begin{array}{l}\text { Hotels and accommodations } \\
\text { availability }\end{array}$ & .323 & 3496 & .001 & .521 & 7.252 & .000 \\
\hline Transportation services & .381 & 4.224 & .000 & .419 & 5.476 & .000 \\
\hline
\end{tabular}

Table 7 showed the comparison of information sources attributes between first-timer visitors and more than once visitors based on the result of F-test regression. Based on the result showed that most of the attributes were significantly affect $(p<0.001)$ the destination's food images more than once except for "Internet/websites" ( $p=0261)$ which means statistically insignificant while first-timer visitors showed the attributes of "Travel magazines" as $p=0.981$ and "Friends and family members" as $p=0.181$ which mean insignificantly effect of this variable. On the other hands, all attributes showed a positive value of beta for both group first-timer and more than once visitors. For instance, changing the brochures and travel guides by one SD while holding other attributes constant would change the dependent variable by 0.176 SD. 
Table 7. Information sources f-test regression

\begin{tabular}{ccccccc}
\hline & \multicolumn{2}{c}{$\mathbf{1}^{\text {st }}$ timer $(\mathbf{N = 1 0 7})$} & \multicolumn{3}{c}{ More than once (N=143) } \\
Information sources & beta & $\begin{array}{c}\text { t- } \\
\text { value }\end{array}$ & sig. & beta & t-value & sig. \\
\hline Brochures and travel guides & .176 & 1.836 & .069 & .353 & 4.481 & .000 \\
Travel books & .319 & 3.445 & .001 & .409 & 5.314 & .000 \\
Travel magazines & .002 & .024 & .981 & .463 & 6.209 & .000 \\
Friends/family members & .130 & 1.346 & .181 & .206 & 2.495 & .014 \\
Highway/airport welcome center & .316 & 3.416 & .001 & .396 & 5.114 & .000 \\
Local/national tourism office & .211 & 2.210 & .029 & .309 & 3.855 & .000 \\
Newspaper & .337 & 3.662 & .000 & .213 & 2.588 & .011 \\
Past experiences & .426 & 4.830 & .000 & .346 & 4.384 & .000 \\
Direct mail from destination & .262 & 2.779 & .006 & .321 & 4.025 & .000 \\
Travel agency/company & .420 & 4.739 & .000 & .448 & 5.947 & .000 \\
Television/ movies/ travel channel & .343 & 3.740 & .000 & .352 & 4.460 & .000 \\
Internet/website & .172 & 1.790 & .076 & .095 & 1.129 & .261 \\
\hline
\end{tabular}

Table 8 showed the comparison among variables overall based on the result of F-test regression. The result showed that Destination's food images as statistically significant $(p<0.05)$ as overall compare to other variables were $(p=0.091)$ for destination's physical images while $(p=0.904)$ for information sources which means statistically insignificant. Failed to reject does not mean accept the null hypothesis since it is established only to proven false by testing the samples of data. On the other hands, all variables reported positive values of beta except for information sources as overall (-0.08). As a result, it showed significant attributes and variables positively related to satisfaction and loyalty.

Table 8. Overall f-test regression result

\begin{tabular}{cccc} 
Attributes & \multicolumn{3}{c}{ Observations ( $\mathbf{N = 2 5 0 )}$} \\
beta & .155 & 2.471 & sig. \\
\hline Destination's food images & .107 & 1.699 & .014 \\
Destination's physical & -.008 & -.121 & .091 \\
images & & & .904 \\
\hline
\end{tabular}

The report came up with several useful conclusions from the results. To begin with, food encounters are an essential part of a tourist's overall satisfaction. The importance of food in tourism is becoming more widely recognised, as it accounts for nearly one-fifth of all positive experiences (Bokunewicz and Shulman, 2017). The findings of this study add to the Malaysian Tourism Board's efforts to promote culinary tourism through a variety of programme such as food events and festivals, cooking classes, and food trips (Jalis et al., 2014).

Second, first-time visitors and repeat visitors to Malaysia have distinctly different viewpoints and intentions toward their visit. Visitors who are visiting for the first time will find the food experience to be more interesting and memorable in terms of their personal tastes and experiences. Zakaria et al (2014) argued that first-time tourists are more prefer to explore the new cultural experiences during their vacation in the destination. As a result, the range of variety ethnic foods available in Malaysia is unsurprisingly something special and unforgettable for tourists as a value-added experience. depending on their tastes, the 
satisfaction of first-time visitors and those who returned more than once for a particular purpose was insignificant. Overall, the results revealed that visitors were extremely satisfied. Both first-time tourists and revisit tourists were enthralled by the sight of traditional foods being cooked, as well as the typical ritual process that occurs during traditional food preparation (Chang et al., 2011). It can represent different elements each time it is performed, giving repeat visitors a unique experience. Furthermore, Sidali et al (2013) mentioned that the style of presentation and preparation might be a new development as attraction and intended to impress or draw tourists. As a result, even repeat tourists will have a different experience when different food operators demonstrate different food preparation processes.

\section{Conclusion}

This study demonstrated how culinary tourism, in combination with other factors, contributes to visitor satisfaction and loyalty in Malaysia. According to the findings of studies by Chi et al (2013); Kim et al (2010), a significant and successful way to attract tourists should be an increase in terms of food, as food is an important element in the tourism industry. The positive perception of food experience among first-time and revisit tourists to Malaysia was demonstrated through local food consumption, and it can be utilized as a tool to promote other tourism items. Some mediums of promotional materials, such as brochures, catalogues, and blogs, should be made accessible and easy to browse for visitors to access information about the different food experiences in Malaysia in order to strengthen in terms of marketing promotion.

Furthermore, the findings of the study suggested that there was a connection between the food picture of a destination and the traveller's intention to return, as well as the degree of satisfaction and loyalty. At the same time, the type of information sources was established. It is used in deciding a traveller's intention to visit a specific destination. Since we live in the age of globalisation, in terms of information sources, most visitors tend to utilize the internet as their primary one. Based on this study regarding information sources, Malaysia also could optimize various channels or mediums related as well as highly recommended especially for the promotion strategy. It is based on the strong relationship between the importance of information sources and intention to visit. In terms of image, it would help to improve the location's overall image if the relevant stakeholders were aware of the impact of the food and physical image of a destination.

Specific food and physical image for a destination's general image can be created. It will add to and help to grow the destination's niche market. As a result of the study's results, which focused on comparing the differences in loyalty and satisfaction between first-time tourists and revisit tourists in terms of loyalty and satisfaction, it could be used to increase the level of management and marketing in the tourism industry. To summarise, a country like Malaysia, which is rich in cultural and heritage history, especially in terms of cuisines, can boost economic performance and tourism industry. It also can develop powerful marketing elements by finding the appropriate and applicable destination's food and physical image and thus providing various sources of knowledge.

\section{References}

Hendijani, B. R. (2016). Effect of food experience on tourist satisfaction: the case of Indonesia. International Journal of Culture, Tourism and Hospitality Research, 10(3), 272-282. 
Björk, P., \& Kauppinen-Räisänen, H. (2016). Interested in eating and drinking? How food affects travel satisfaction and the overall holiday experience. Scandinavian Journal of Hospitality and Tourism, 17(1), 9-26.

Bokunewicz, J. F., \& Shulman, J. (2017). Influencer identification in Twitter networks of destination marketing organizations. Journal of Hospitality and Tourism Technology, 8(2), 205-219.

Chang, R. C. Y., Kivela, J., \& Mak, A. H. N. (2011). Attributes that influence the evaluation of travel dining experience: When East meets West. Tourism Management, 32(2), 307316.

Chi, C. G.-Q., Chua, B. L., Othman, M., \& Karim, S. A. (2013). Investigating the Structural Relationships Between Food Image, Food Satisfaction, Culinary Quality, and Behavioral Intentions: The Case of Malaysia. International Journal of Hospitality \& Tourism Administration, 14(2), 99-120.

Everett, S., \& Slocum, S. L. (2013). Food and tourism: an effective partnership? A UK-based review. Journal of Sustainable Tourism, 21(6), 789-809.

Guthrie, J., Mancino, L., \& Lin, C.-T. J. (2015). Nudging Consumers toward Better Food Choices: Policy Approaches to Changing Food Consumption Behaviors. Psychology \& Marketing, 32(5), 501-511.

Hjalager, A.-M., \& Johansen, P. H. (2013). Food tourism in protected areas - sustainability for producers, the environment and tourism? Journal of Sustainable Tourism, 21(3), 417433.

Horng, J.-S., \& Tsai, C.-T. S. (2011). Culinary tourism strategic development: an Asia-Pacific perspective. International Journal of Tourism Research, 14(1), 40-55.

Hwang, J. (2016). Organic food as self-presentation: The role of psychological motivation in older consumers' purchase intention of organic food. Journal of Retailing and Consumer Services, 28, 281-287. doi:10.1016/j.jretconser.2015.01.007.

Jalis, M. H., Che, D., \& Markwell, K. (2014). Utilising Local Cuisine to Market Malaysia as a Tourist Destination. Procedia - Social and Behavioral Sciences, 144, 102-110. doi:10.1016/j.sbspro.2014.07.278.

Ji, M., Wong, I. A., Eves, A., \& Scarles, C. (2016). Food-related personality traits and the moderating role of novelty-seeking in food satisfaction and travel outcomes. Tourism Management, 57, 387-396.

Kim, Y. G., Suh, B. W., \& Eves, A. (2010). The relationships between food-related personality traits, satisfaction, and loyalty among visitors attending food events and festivals. International Journal of Hospitality Management, 29 (2), 216-226.

Lee, A. H. J., Wall, G., \& Kovacs, J. F. (2015). Creative food clusters and rural development through place branding: Culinary tourism initiatives in Stratford and Muskoka, Ontario, Canada. Journal of Rural Studies, 39, 133-144. doi:10.1016/j.jrurstud.2015.05.001.

Lee, I., \& Arcodia, C. (2011). The Role of Regional Food Festivals for Destination Branding. International Journal of Tourism Research, 13(4), 355-367.

Long, L. (2004). Culinary Tourism. Lexington, The University Press of Kentucky.

Mak, A. H. N., Lumbers, M., \& Eves, A. (2012). Globalisation and food consumption in tourism. Annals of Tourism Research, 39(1), 171-196.

Musa, G. (2000). Tourism in Malaysia. In C. M. Hall, \& S. Page (Eds.), Tourism in South and South East Asia (pp. 144-156). Oxford: Butterworth-Heinemann.

Rajendran, S. D., \& Wahab, S. N. (2017). Purchasing Intention towards Green Packaged Products: An Exploratory Study among Malaysian Consumers. 3rd International 
Conference on Advanced Research in Business and Social Sciences, 29-30 March, pp. 347-355, Langkawi, Malaysia.

Rong-Da Liang, A., Chen, S.-C., Tung, W., \& Hu, C.-C. (2013). The Influence of Food Expenditure on Tourist Response to Festival Tourism: Expenditure Perspective. International Journal of Hospitality \& Tourism Administration, 14(4), 377-397.

Seo, S., \& Yun, N. (2015). Multi-dimensional scale to measure destination food image: case of Korean food. British Food Journal, 117(12), 2914-2929.

Sidali, K. L., Kastenholz, E., \& Bianchi, R. (2013). Food tourism, niche markets and products in rural tourism: combining the intimacy model and the experience economy as a rural development strategy. Journal of Sustainable Tourism, 23(8-9), 1179-1197.

Sotiriadis, M. D. (2015). Culinary tourism assets and events: suggesting a strategic planning tool. International Journal of Contemporary Hospitality Management, 27(6), 12141232.

Thielke, S., Harniss, M., Thompson, H., Patel, S., Demiris G., \& Johnson, K. (2012). Maslow's Hierarchy of Human Needs and the Adoption of Health-Related Technologies for Older Adults. Ageing International, 37, 470-488. https://doi.org/10.1007/s12126-011-91214.

Wahab, S. N., Rajendran, S. D., Yeah, N. K., \& Deng, Y. (2017). Antecedents Influencing EService Quality towards Customer Loyalty among Malaysian Online Shoppers. 3rd International Conference on Advanced Research in Business and Social Sciences, 29-30 March, pp. 337-346, Langkawi, Malaysia.

Zakaria, A. Z., Salleh, I. H., \& Rashid, M. S. A. (2014). Identity of Malay Garden Design to be Promoted as the Cultural Tourism Product in Malaysia. Procedia - Social and Behavioral Sciences, 153, 298-307. doi:10.1016/j.sbspro.2014.10.063.

Zaman, K., Moemen, M.A., \& Islam, T. (2016). Dynamic linkages between tourism transportation expenditures, carbon dioxide emission, energy consumption and growth factors: evidence from the transition economies. Current Issues in Tourism, 20(16), 1720-1735. 